\title{
Challenges faced by Women With Visual Impairment in Living a Sustainable Livelihood
}

\author{
by \\ Hildah Kachaka and Mwiya Liamunga Imasiku
}

\section{ABSTRACT}

The nature of the challenges faced by women with visual impairments remains uncertain. However, studies have been done on women with disabilities in general but none has focused on women with visual impairments. This study sought to establish the challenges faced by women with visual impairments in living a sustainable livelihood in urban areas.

A descriptive survey design was used in order to obtain a true and comprehensive picture of individuality. Primary data was collected through interview schedules and questionnaires.

Data was collected from women with visual impairments in selected government line ministries. For those not in employments, data was collected from the central business district where they parade to ask for alms from well wishers.

The target sample was all women with visual impairments registered with the Federation for the Blind and based in Lusaka urban. Stratified sampling was used to classify women with visual impairments into their economic status such as those in formal employment and those not working at all.

Sixteen $(50 \%)$ of women with visual impairments were in formal employment while sixteen $(50 \%)$ were on the street begging. Twenty-one $(66 \%)$ of the women with visual impairment revealed that they were not able to live a sustainable livelihood due to the different challenges they faced while eleven (44\%) stressed that they were managing because they had a salary though it was not enough to cater for their basic needs. From the findings it has been noted that women with visual impairments have a lot of challenges on sustainable livelihood. Sixty-six $(66 \%)$ of the women stated that they were not able to live a sustainable livelihood, as most of them depended on begging for their livelihood. The money they realised from begging could not meet all their basic needs. The findings also reveal that the women with visual impairments despite their level of education, could not be offered any other job apart from being telephone operators. From the sixteen $(50 \%)$ of women with visual impairments who are in formal employment, eleven (69\%) had attained grade nine while five (31\%) were grade twelve school leavers and yet they were doing the same job. The grade twelve school leavers felt unfairly treated because sight had disadvantaged them in the area of wanting to do other professions of their dreams. Further, it was found that there were some cultural factors that contribute to the challenges women with visual impairments face. In as much as they know that they have no sight, they feel they must be appreciated as human beings just like the women with sight. The findings show that 
twenty $(63 \%)$ of all the participants indicated that they were discriminated, segregated and abused by the sighted in different ways. Eleven (35\%) of the women with visual impairment stated that as they were growing up, they were over-protected and overlooked and this had contributed to their poverty situation today.

The results of the study indicate that there is a strong relationship between being visually impaired and sustainable livelihood among women despite their education levels. The study has also revealed that although there is so much awareness on disability issues, women with visual impairments are still discriminated and excluded from the mainstream activities. Therefore, stakeholders in disability issues should address the plight of these women. Recommendations made include:

(a) Government and stakeholders in the welfare of women with visual impairments should ensure that information on Citizen Economic Empowerment is transcribed into Braille if the visually impaired are to benefit from the scheme.

(b) Government through appropriate authorities should reduce the number of procedures involved in accessing the funds.

(c) Since education is a factor in improving the livelihood of an individual, government through relevant ministries should build more schools and provide bursaries and or scholarships to the visually impaired to attain vocational training.

(d) The visually impaired who have attained high school level should be allowed to venture into careers of their choice.

\section{INTRODUCTION}

This study sought to focus attention on challenges faced by women with visual impairment in attaining a sustainable livelihood in Lusaka urban. Visual impairment is a disability which refers to having difficulty with sight in one or both eyes or not seeing at all (Heward and Orlansky, 1988). Disability itself is any restriction or lack of ability to perform any activity in the manner within the range considered normal for human beings (ILO, 2006). Women with visual impairment have double vulnerability in the sense that firstly, they are women, a group among the disadvantaged. Secondly, they have a disability which is a challenge and places them in a disadvantaged position (Nkombo and Mwape, 2003). Sustainable livelihood is having the ability to continue in the future in terms of securing access to the basic services and activities pursued by an individual or household to increase levels of wealth, flow of food and other resources to provide for sustainable security against impoverishment (Carney, 1998). Women everywhere, disabled or not need a fair chance to earn their own livelihood as men (Llagan, 2002). Despite increasing awareness on disability, disabled people continue to face daily violations of their human rights including the right to decent livelihood and health care which is the first step towards self reliance and independence (Llagan, 2002).

In Zambia studies have been carried out on women with disabilities in general but none has focused on women with visual impairments in particular. The status of women with visual impairment reflects their position as an oppressed group in terms of educational opportunities, vocational training programmes access, 
occupation attainment and economic status (Kalabula, 2006). Women with disability experience more discrimination than other women because of being unable to live up to the demanding ideals of womanhood imposed by society. The current study was conducted to explore the challenges faced by women with visual impairements in living a sustainable livelihood.

\section{OBJECTIVES}

1. To establish views of women with visual impairments on sustainable livelihood.

2. To assess how Citizen Economic Empowerment fund has impacted on women with visual impairments in living a sustainable livelihood.

3. To determine contributing factors to the challenges faced by women with visual impairments in living a sustainable livelihood.

4. To establish how cultural factors contribute to the challenges faced by women with visual impairments in living a sustainable livelihood.

\section{PURPOSE OF THE STUDY}

The purpose of the study was to find out the challenges faced by women with visual impairments in Lusaka urban and coping strategies.

\section{METHODOLOGY}

\section{Study Design}

The study used a descriptive survey design because it is potentially the most valuable method known for obtaining a true and comprehensive picture of individuality.

\section{Sample}

The target population was women with visual impairments registered with The Federation for the Blind and based in Lusaka urban. The sample size was thirty-five respondents. Thirty-two women were purposively selected from the register and then stratified sampling was used to classify them into those working and not working at all. Convenience sampling was used on the key informants.

\section{Instruments}

Interview schedule technique was used to collect data from women with visual impairments. It utilised both open and closed ended questions to allow respondents to express themselves freely and to generate respondents' experiences. Semi-structured questions were also asked to help in the collection of in-depth data. Structured questionnaires were used on key informants. Secondary data was also collected from library materials on related literature on women with disabilities and not necessarily women with visual impairments. 


\section{Data Analysis}

In regard to this study, analysis of data was realised from the answers given from interview schedules and questionnaires. Answers were analysed quantitatively and qualitatively with a focus to establish challenges faced by women with visual impairments in living a sustainable livelihood. In analysing the data collected, qualitative analysis was used in discussing various responses given by respondents then coming up with common themes. Quantitative analysis was used in analysing responses using the Statistical Package for Social Sciences (SPSS), as well as computer-generated tables of frequencies and percentages in distribution of the variables which were presented in the form of tables and pie charts.

\section{Ethical Considerations}

The study involved people with disabilities. For this reason the researcher recognised the fact that disability issues were sensitive and associated with stigma, exclusion and discrimination, as such the principle of informed consent was observed in line with research ethics. Before the respondents were asked to participate they were informed about the purpose and focus of the study and consent to participate was sought from them. All respondents remained anonymous was in order to maintain confidentiality.

\section{RESULTS}

Table 2: View on Sustainable Livelihood

\begin{tabular}{|l|c|c|}
\hline \multicolumn{1}{|c|}{ Definition } & Frequency & Percentage \\
\hline Not sure & 2 & 06.3 \\
\hline How one manages their way of life & 2 & 06.3 \\
\hline Having a job to sustain ones living & 10 & 31.3 \\
\hline $\begin{array}{l}\text { To be able to look after your family and } \\
\text { meet their basic needs }\end{array}$ & 18 & 56.3 \\
\hline Total & $\mathbf{3 2}$ & $\mathbf{1 0 0 . 0}$ \\
\hline
\end{tabular}

Source: Field Data, 2012

The table above shows that eighteen (56\%) stated that 'to be able to look after your family well and meet all their basic needs, ten (31\%) said "having enough to live on while two $(6 \%)$ said how one manages their life and the other two $(6 \%)$ were not sure of what to say. 


\section{Figure 1: Whether Respondent is Able to Live a Sustainable Livelihood}

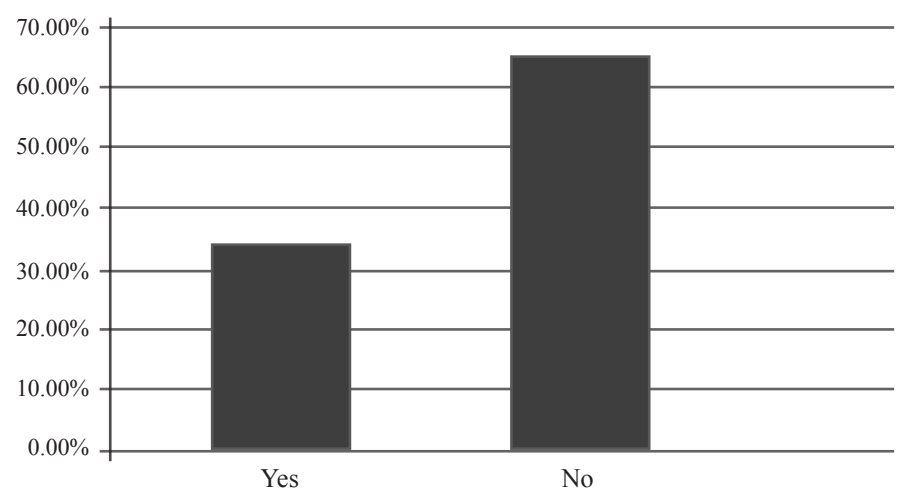

Source: Field Data, 2012

The figure shows that majority of women with visual impairment twenty-one (65.6\%) said 'no' while eleven (34.4\%) said 'yes'. A further question was asked to those who said yes on how they were managing to live a sustainable livelihood.

\section{Table 3: How Respondents Manage to Live a Sustainable Livelihood}

\begin{tabular}{|l|c|c|}
\hline \multicolumn{1}{|c|}{ Response } & Frequency & Percentage (\%) \\
\hline I am on a salary & 10 & 90.9 \\
\hline It's a struggle & 1 & 9.1 \\
\hline Total & $\mathbf{1 1}$ & $\mathbf{1 0 0 . 0}$ \\
\hline
\end{tabular}

Source: Field Data, 2012

The table above shows that ten (91\%) of those who said 'yes' were on a salary while one $(9 \%)$ said it was a struggle. A further question was asked to those who said they were not able to live a sustainable livelihood.

\section{Table 4: Reasons for Failing to Live a Sustainable Livelihood}

\begin{tabular}{|l|c|c|}
\hline \multicolumn{1}{|c|}{ Reasons } & Frequency & Percentage \\
\hline Salary not enough to meet all my needs & 5 & 24 \\
\hline We depend on begging and well wishers & 16 & 76 \\
\hline Total & $\mathbf{2 1}$ & $\mathbf{1 0 0 . 0}$ \\
\hline
\end{tabular}

Source: Field Data, 2012

Table 4 above shows that majority of the respondents sixteen (71\%) said they depended on begging and could not meet their basic needs while five $(29 \%)$ said their salary was not enough to meet all their needs. 


\section{Figure 2: Some Cultural Factors Contributing to the Challenges Faced by Women with Visual Impairments.}

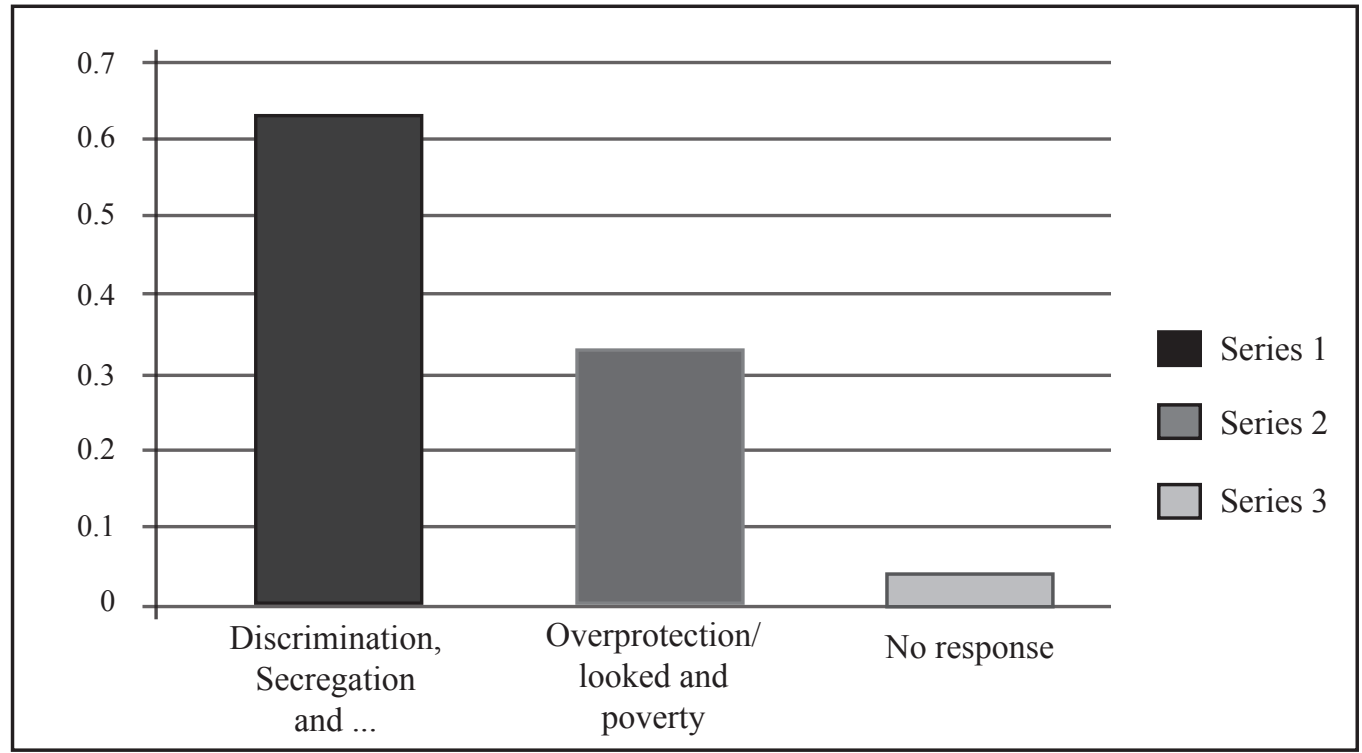

Source: Field Data, 2012

The figure above shows that the majority twenty (63\%) stated that discrimination, segregation and abuse while eleven (35\%) said overprotection, being overlooked and hence poverty stricken.

\section{DISCUSSION}

As regards the findings presented in this article, the age distribution of the respondents were twenty-four (75\%) ranged from 36 - 55 years old. These are the years when one is fully charged with the responsibilities of taking care of a family and should be in the establishment period. Four (12.5\%) were between 26 - 35 years which are the reproductive years and this can be connected to the large families they keep while four $(12.5 \%)$ were above 55 years, which means one has reached retirement and are no longer working. In discussing women's views on sustainable livelihood, eighteen (56\%) stated that 'it was to look after your family well and meet all their basic needs. This finding is in line with how (Musanjala, 2007), defined livelihood. He stated that livelihood is a means of living and capabilities, assets and activities required. He further stated that livelihood encompassed income as well as social institutions, gender relations and poverty rights required to support and sustain a certain standard of living. It includes access and benefits from social and public services provided by the state such as education, health services and other infrastructure. While ten (31\%) said having enough to live on and meet basic needs and two $(6 \%)$ said how one manages their life and then two (6\%) were not sure.

A further question was asked to the respondents if whether they were able to live a sustainable livelihood. Twenty-one (65\%) of the respondents said 'no' they were not 
able to live a sustainable livelihood while eleven (34.4\%) said 'yes' they were able to live a sustainable livelihood. A further question was asked as to how respondents managed to live a sustainable livelihood. Ten (91\%) of those who said they were able to live a sustainable livelihood indicated that they managed because they were on a salary. This finding conforms to what Musanjala (2007) stipulates a livelihood. He stated that a livelihood encompasses income. While one (9\%) said that it was a struggle.

A further question was asked to those who said they were unable to live a sustainable livelihood and health care. Sixteen (71\%) said they depended on begging and well wishes and so could not meet their basic needs while five $(29 \%)$ said their salary was not enough to meet all their basic needs. In discussing the challenges faced by women with visual impairments another striking issue which was highlighted was the effects of their education level. The study revealed that from eleven (34\%) of those who attained primary education could literally do nothing but resort to begging as a livelihood. Fifteen (47\%) of women who attained grade nine, some were on the streets begging while others were employed as telephone operators. In the same vein, five $(16 \%)$ of those who were grade twelve school leavers were also employed as telephone operators, a thing they did not like and felt discriminated and excluded from the mainstream jobs. This finding conforms to what Mwape and Nkombo (2003), stipulated by saying when education is made available to the disabled women; it perpetuates a traditionally narrow role of women. As such this kind of education hinders the visually impaired from venturing into other fields apart from switchboard operating. This is also as a result of not having many schools for the visually impaired and many specialised teachers for the visually impaired. Additionally, there are not enough learning and teaching material for the visually impaired as the materials are said to be expensive. Kalabula (2006), also postulates that the status of women with visual impairment reflects their position as an oppressed group in terms of educational opportunities, vocational training programmes access, rehabilitation, occupational attainment, economic status and social outlets.

Cultural factors of discrimination, segregation and over-protection was another issue which contributed to the challenges faced by women with visual impairments. Twenty (63\%) of the women stated that they felt discriminated, excluded, segregated and abused while eleven (34\%) stated that they were over-protected and over-looked and as such it has contributed to their poverty levels. This finding is in line with what Anderson (1968) observed on people with disabilities. He observed that people with disabilities are either rejected or even destroyed for being indifferent, or are less protected and less provided with any social services compared to the non-disabled persons in society. They are perceived to be an eye sore to society and are always excluded from participating in any form of planning for national development. Similarly, Hegarty (1998), observed that people with disabilities are more often excluded from the mainstream society and denied equal access to education, employment and family life and leisure activities. Culture has a tendency of discrimination and segregation, here is the crying out of one of the disabled woman for her rights as a human being: 
'As I fight my rights, I have a double war for I am a woman with disabilities... you denied me initiation into womanhood as I was growing up. You denied me my duties of doing house chores, cultivating and collecting firewood... as every woman is fighting for her right too, I stand to fight. Allow me to be independent and earn my own bread' (Mwape and Nkombo, 2003).

\section{CONCLUSION}

The findings of the study have revealed that despite the visually impaired women knowing what sustainable livelihood is, they are not able to live up to it due to the many challenges they encounter. Even those in employment disclosed that they were not able to live a sustainable livelihood because their salaries were insufficient to meet all daily basic needs. The study has also revealed that despite increasing awareness on disability, disabled people continue to face daily violation of their human rights especially the right to decent life based on the findings, the study makes the following recommendations:

- Government and stakeholders in the welfare of women with visual impairments should ensure that information on Citizen Economic Empowerment is transcribed into Braille if the visually impaired are to benefit from the scheme.

- Government through appropriate authorities should reduce the number of procedures involved in accessing the funds.

- Since education is a factor in improving the livelihood of an individual, government through relevant ministries should build more schools and provide bursaries and or scholarships to the visually impaired to attain vocational training.

- The visually impaired who have attained high school level should be allowed to venture into a career of their choice.

\section{REFERENCES}

Carney, D. (1998), Sustainable Rural Livelihood. London: DFID.

Heward and Orlansky (1988), The Exceptional Student. London: Merril.

ILO (2006), People with Disabilities: Pathway to Decent Work, Workshop, Lusaka. Kalabula, D.M. (2006), Inclusive Education in Africa: A Myth or Reality, Zambian Case Study on Including the Excluded.

Llagan, V.M. (2002), The Asian and Pacific Decade of Disabled Persons: An NGO Perspective.

Mwape and Nkombo (2003), Vocational Needs for Women with Disabilities. A Case of Lusaka and Southern Provinces, ZAMSIF, Lusaka. 